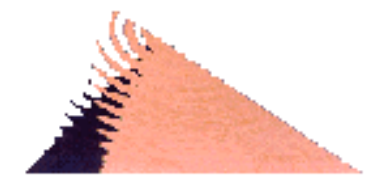

\title{
La profesión periodística ante los intereses de la estructura informativa. Una aproximación al tema
}

\author{
Dra. Aurora Labio Bernal \\ (C) Profesora Asociada del Departamento de Periodismo - Universidad de Sevilla
}

RESUMEN

La autora realiza en este artículo un análisis de la profesión periodística en España apoyándose en el estudio de sus orígenes, en los problemas que la aquejan como gremio y en la situación en la que se encuentra dentro de la estructura informativa de nuestro país. El objetivo es invitar a los profesionales de la información a reflexionar sobre las dificultades y presiones a las que se ven sometidos, con la idea de extraer de la autocrítica las posibles soluciones que devuelvan al periodista su auténtica función en la sociedad.

\section{ABSTRACT}

This article analyses journalistic profession in Spain relating the study of its origins, nowdays problems as union and its situation inside the informative structure. The present study try to invite the information professionals to meditate on difficulties and pressures in media. From this premise, it could be possible to extract a self-criticism and solutions that made journalists return to their authentic function in society.

Palabras claves: Periodistas/Profesión/Origen/Problemas/Poder/Política.

Key words: Journalist/Profession/Origins/Problems/Power/Policy.

\section{Introducción}

El análisis de la actual situación de la profesión periodística requiere detenerse en tres elementos que consideramos fundamentales. En primer lugar, resulta de interés trazar una perspectiva histórica del origen de la profesión en España, de donde podemos extraer el punto de partida de los problemas que aquejan hoy al gremio periodístico. En segundo lugar, se plantea como una cuestión de interés realizar una radiografía de la situación laboral en la que viven muchos informadores, lo que nos permitirá conocer la auténtica realidad de una profesión mitificada. Como tercer elemento, consideramos necesaria la descripción de aquellas presiones internas y externas, políticas y económicas, que afectan el normal desarrollo de la labor informativa, lo que se traduce en un recorte de las libertades del profesional y puede llegar a afectar a su ámbito privado.

Estas tres cuestiones descritas más arriba constituyen los ejes fundamentales, aunque no los únicos, para conocer cuál es el estado de la profesión periodística actual. En efecto, el conocimiento de lo que fuimos y, más concretamente, de la articulación del gremio periodístico como tal a finales del siglo XIX, se nos descubre como la herencia inmediata de muchas de las cuestiones que hoy se siguen debatiendo en los congresos de periodistas.

Esta herencia arrastra, pues, muchos de los problemas con los que se enfrenta el informador pero, a ello, además, hemos de unir otros elementos propios de nuestra época y derivados de la configuración de la actual estructura informativa.

De esta forma, la conjugación de los problemas heredados con las dificultades de la práctica actual dibujan un panorama periodístico sobre el que hay que reflexionar para buscar posibles soluciones. El ritmo vertiginoso del universo informativo hace, además, que muy pocas veces se realice este ejercicio de autoanálisis, necesario para que el periodista mejore sus condiciones profesionales pero, sobre todo, para que no olvide nunca la importante labor que desarrolla de cara a la sociedad. 
Nos tenemos que remitir al siglo XIX para encontrarnos con los primeros profesionales de la información (1) que, además, empiezan a tomar conciencia de ello. Antes de esto, la prensa no tenía mucho que ver con la de hoy, y los que se encargaban de redactar lo hacían sin tener conciencia de estar realizando una profesión.

Con el nacimiento del periodismo moderno, es decir, un periodismo que no depende del ejecutivo para ponerse en marcha y que no va a ser castigado por este poder en relación a sus delitos, es cuando nos vamos a encontrar con el afianzamiento de la profesión. Es a partir de la Restauración, cuando la prensa se convierte en ese nombrado cuarto poder y es ahora también cuando los profesionales van a tomar conciencia de ello.

Durante el último tercio del siglo XIX, el periodismo es visto como símbolo de libertad y progreso. Ya no hay censuras ni controles como en épocas pasadas, de tal forma que al producirse una mayor independencia, el periódico termina convirtiéndose en un producto detrás del cual hay unos trabajadores: los periodistas, que tienen que luchar por proteger y dignificar su situación.

Por eso también surge el interés por la formación y es ahora cuando se publica el Manual del perfecto periodista, escrito en 1892. Además, empieza a surgir también el interés por los datos relativos a la profesión: es decir, por el número de periodistas que trabajan en una ciudad, en una región, en un país concreto. También nuestros profesionales empiezan a poner sus ojos en la labor que se realiza en otros países, como Estados Unidos, que por aquel entonces estaba metido ya de lleno en el periodismo como negocio, con grandes tecnologías y un enfoque espectacularmente distinto a lo que se vivía en nuestro país.

Además, empiezan a producirse adelantos técnicos que se aplicarán al periódico y que van a dar como resultado una mejora de calidad y cantidad en los productos.

A finales del siglo XIX, por tanto, estamos asistiendo al desarrollo del periodismo y, como consecuencia derivada, al desarrollo de la profesión de periodistas. Empiezan a surgir así los primeros corresponsales de guerra al tiempo que se plantean las reflexiones sobre la situación laboral, sobre todo porque comienzan a detectarse verdaderos síntomas de precariedad en el empleo.

Debido precisamente a esta precariedad se construyen los primeros montepíos de periodistas, como lugares de retiro para los viejos profesionales de la información, que servían como residencias o asilos. Esta idea del montepío, sin embargo, será superada algunos años después y dará paso a las asociaciones de la prensa a partir de la Ley de imprenta de 1883, que contemplaba la creación de asociaciones para fines religiosos, políticos, científicos, artísticos y de recreo o cualesquiera otros lícitos, que no tuvieran por objeto el lucro o la ganancia.

De igual manera, también se inicia la preocupación por el desempeño de la propia labor profesional, no ya desde el punto de vista social, sino desde el punto de vista periodístico. Para reflexionar acerca de lo que están haciendo, los profesionales de la información organizan también a finales de este siglo congresos, como el celebrado en 1894 en Amberes bajo el título de Primer Congreso Internacional de la Prensa (2).

El objeto de este congreso era procurar una reunión de periodistas de todos los países y la adopción de medios encaminados a favorecer el desarrollo de los intereses materiales de la prensa, además de elevar la dignidad de la profesión. Entre algunos de los países que acuden nos encontramos a representantes de Inglaterra, Austria, Italia y Francia y la propia España.

Además, se plantean también las cuestiones jurídicas en las que se puede ver implicado el profesional y se fija la profundización para próximos congresos de cuestiones tales como el derecho de rectificación, la difamación y la injuria.

Uno de los últimos elementos que podemos citar en el desarrollo de la profesión periodística que se articula en estos años es el referente al planteamiento sobre las consecuencias que sobre el receptor puede acarrear la profesión periodística.

La descripción de estos primeros años en el desarrollo de la profesión pone de manifiesto la existencia de una serie de problemas que aquejan a los periodistas y que presenta ciertas semejanzas con la situación actual aunque, evidentemente, existan matices diferentes.

La situación actual: radiografía de la profesión periodística

Evidentemente, las deficiencias que se han ido arrastrando a lo largo de todo este siglo se han acumulado como parte del malestar de un colectivo profesional cada vez más asentado. Si antiguamente los periodistas eran trabajadores poco organizados y con escasa preparación en la mayoría de los casos, en la actualidad se han convertido en un grupo profesional cada vez más cualificado (sólo hay que pensar que el título de licenciado se está convirtiendo en requisito indispensable para acceder al trabajo) y que se está haciendo eco de una serie de problemas a los que está buscando solución.

En efecto, nos encontramos en la práctica diaria de muchos profesionales una serie de problemas que están siendo motivo de 
reflexión en muchos congresos y que podemos resumir en varios puntos.

En primer lugar, nos encontramos con la inexistencia de un marco legal para la profesión. Sólo la prensa periódica no diaria posee un convenio marco estatal. Para el resto, prensa diaria, agencias, radio y televisión no hay ningún marco legal que ampare a sus trabajadores. En la mayoría de los casos, estos se rigen por convenios de empresas, lo que los dota de cierta arbitrariedad y deja a establecer diferentes categorías en la profesión.

En la actualidad se está negociando entre la AEDE (Asociación de Editores de Diarios Españoles, la patronal) y los sindicatos un convenio colectivo para la prensa diaria, cuya aprobación estaba prevista para la primavera de 2001.

Si se analizan los distintos planteamientos previstos en los borradores, se presenta complicada la aprobación de un convenio consensuado que sea del agrado de las dos partes. No queremos extendernos en esta cuestión, pero sí es oportuno recoger algunas de las diferencias planteadas.

En el ámbito funcional, mientras los sindicatos hablan de convenio colectivo, la AEDE habla de convenio en aquellas empresas no afectada por convenio propio, con lo que sigue dejando a muchos trabajadores al arbitrio de sus empresas.

Mientras, en el ámbito personal, los sindicatos reconocen que se regirán por el convenio tanto los redactores como los trabajadores de impresión y distribución, además de los corresponsales y colaboradores con contrato civil y colaboradores a la pieza. La AEDE excluye precisamente del convenio a estos colaboradores y corresponsales, reduciendo el ámbito de aplicación y dejando a estos trabajadores en una situación de irregularidad.

En cuanto a la contratación e ingreso, los sindicatos hablan de contratación indefinida, mientras que la patronal habla de la utilización de los diversos modos de contratación de acuerdo con la finalidad de cada uno de los contratos.

También la jornada de trabajo se ve de diferente manera. Los sindicatos hablan de 35 horas semanales, mientras la patronal habla de horas anuales, 1.644, que salen a más de 7 horas por jornada. Además, los sindicatos hablan de 15 minutos de descanso por jornada y de dos días de descanso, preferentemente sábados y domingos. La AEDE omite el descanso de 15 minutos y establece un descanso semanal rotativo, de lunes a domingo.

En relación a las vacaciones y festivos, en ambos casos se habla de 30 días por año, pero de nuevo se establecen diferencias. Los sindicatos hablan del período de disfrute de las vacaciones entre julio, agosto y septiembre, aunque contemplen también el acuerdo entre empresa y trabajadores para disfrutar del período vacacional en otra época del año.

Desde la AEDE se deja claro que será cada empresa la que fijará el calendario de vacaciones. Además, los sindicatos contemplan también los días festivos en los que trabaje el periodista, estableciendo una compensación de dos días de descanso por festivo trabajado. La AEDE omite cualquier comentario a los días festivos.

En el punto referente a las horas extraordinarias, los sindicatos hablan de horas extraordinarias ordinarias, mientras que la patronal habla en términos de jornada anual pactada. Además, los sindicatos piden una compensación en descanso o en salario, algo que además será decidido por el trabajador.

La consideración de las horas extraordinarias también es distinta, ya que los sindicatos hablan de tales como las que sean necesarias para la finalización de una tirada o las producidas por avería, noticia extraordinaria o cualquier otra causa determinada no imputable a la organización de la producción.

Precisamente, la AEDE no considera estas horas como extraordinarias, al tiempo que habla de una compensación preferentemente en descanso, y siempre que ello no perturbe el normal proceso productivo de la empresa.

Sobre el régimen retributivo, coinciden en el salario base más los complementos, aunque los sindicatos contemplan también las indemnizaciones o compensaciones de carácter no salarial (por ejemplo, el descanso).

En cuanto al salario, los sindicatos hablan de salario como cantidad bruta que recibe el trabajador por todos los conceptos, y seguidamente hablan de los complementos por antigüedad (por ejemplo, los quinquenios).

En este punto, la AEDE habla de salario base, al que aplicará una serie de complementos:

a) el personal (propio de cada empresa). Aquí se incluyen la antigüedad y otros como puede ser el reconocimiento del título.

b) Los complementos de puesto de trabajo, como el de nocturnidad y el de trabajo en domingo.

Los sindicatos hablan de:

a) Plus de libre disposición. No contemplado por la AEDE y que reconoce la situación de muchos profesionales que están a disposición de la empresa en todo momento para cubrir necesidad informativas de carácter eventual. 
b) Plus de dedicación exclusiva, con su correspondiente compensación.

La AEDE engloba estos dos complementos dentro de uno solo, el de mayor calidad y/o cantidad de trabajo, pero no especifica en ningún caso las compensaciones o retribuciones de los mismos.

En el plus de nocturnidad, sindicatos y AEDE coinciden, mientras que en el del descanso dominical, los sindicatos son más explícitos y establecen un plus de 10.000 pesetas por domingo trabajado. La AEDE lo deja en virtud de aquella cantidad que se viniera entregando a la firma del convenio.

Por último, cuando hablan de los grupos profesionales, las diferencias se establecen en las nomenclaturas y también en cuanto a la forma de organizar estos grupos.

Así, los sindicatos lo hacen según la distinta función de los trabajadores en un periódico:

-técnicos.

-personal de redacción, donde incluyen tanto a periodistas, como a jefes de sección y ayudantes de redacción.

-personal de administración.

-personal de talleres.

-personal de servicios generales.

La AEDE establece los grupos respondiendo a una jerarquía:

-en el grupo I, mezcla y pone al mismo nivel a los chóferes y limpiadores que al auxiliar de redacción o redactores en prácticas.

-en el grupo II, mezcla al promotor de ventas con el documentalista, el oficial de primera, el ayudante de redacción y el redactor de segunda.

-en el grupo III, incluye a todos los jefes (tanto de publicidad, como de distribución) y los redactores y jefes de sección.

-en el grupo profesional IV, incluye a los subdirectores, a los directores y a los redactores jefes.

La comparación de estos dos borradores nos confirma la existencia de una indefensión legal, que hace que la profesión se mueva dentro de una gran precariedad laboral. Los periodistas viven en función de la empresa, y se les contrata en situación de prestación de servicios, cuando en realidad pueden estar a tiempo completo en la redacción. Abundan los contratos temporales o de obra y las becas ficticias, a falta de una regulación del sector.

Todo este panorama se ve agravado además por el desempleo en la profesión, a lo que contribuye el intrusismo y la falta de regulación en cuanto a las vías de acceso a la profesión.

Al sumar todos estos elementos, tenemos una profesión mal retribuida que, además, puede pagar también el coste de su profesión laboral a través del sacrificio de la libertad de expresión del periodista.

El miedo al despido, ante la inexistencia de un marco legal, no sólo provoca el proselitismo ideológico con el medio, sino también, en algunos casos, la falta de otras libertades, como puede ser la de expresión y la sindical.

La importancia de todos estos problemas no radica sólo en el periodista como integrante de un gremio profesional, sino que se extiende más allá desde el momento que se reconoce la función social que realiza en el desempeño de su trabajo diario. El producto elaborado por el periodista, la información que llega finalmente al público, se contamina así de estas deficiencias y problemas, lo que terminará afectando finalmente a la sociedad en su conjunto. La resolución de los problemas que aquejan a la profesión no son, por tanto, sólo cosas de un colectivo, sino que también interesan a la sociedad desde el momento que es ésta la que recibe y se nutre de la información que diariamente realiza el periodista.

El periodista y la estructura informativa: la intromisión del poder económico y político

El mundo de los medios de comunicación está dominado por cuestiones que pueden ir más allá de la labor periodística. Los medios, la prensa, ya no es el cuarto poder, sino que se ha convertido en parte del primer poder al relacionarse íntimamente con cuestiones económicas y políticas.

La presión económica puede venir marcada desde el momento que el medio pertenece a una estructura empresarial con unos interese determinados y que se plantea como negocio que debe producir unos beneficios. De esta forma, la publicidad y la 
situación financiera de la empresa marcarán la pauta de los trabajadores, y el periodista no se podrá quedar al margen.

Si esto ocurre con la trama económica, la política también resulta interesan-te, desde el momento que vemos que en el mundo del periodismo, los profesionales de la información se dan la mano con los miembros de la clase política del país y los medios de comunicación defienden los intereses de un partido o de otro. No estamos en el siglo XIX, en el que las cabeceras se subtitulaban a sí mismas como "órganos de expresión" de los distintos partidos políticos, pero sí es cierto que esta leyenda puede entenderse de manera implícita. Tal y como reconoce el profesor Ramón Reig:

"Los medios de comunicación del grupo Prisa se levantan todas las mañanas con el prejuicio de que la 'derecha', como dicen, más en concreto, el Partido Popular, es un elemento negativo, casi todo lo hace de forma negativa y hay que buscarle a la noticia la forma de enfocarla contra 'la derecha'. El Mundo, Abc, creen que es el PSOE el elemento a 'batir'. Los medios públicos bailan, como se sabe también, al son de las siglas que gobiernen. Es decir, el bipartidismo se traslada a la información tanto a nivel de medios estatales como regionales y locales."(3).

Lo preocupante de todo esto es que la información emitida por el medio en cuestión se ofrece en virtud de estos criterios políticos y aparece, inevitablemente, la manipulación. De esta manera, la independencia del profesional de la información, de ese periodista ajeno a la ideología de su medio, desaparece y se sustituye por la de un informador que muestra su adhesión, a veces descarada, al partido de turno.

De esta manera, el periodista se ve abocado a convertirse en una pieza más del engranaje que hace funcionar al sistema, con lo que su función como contrapoder pierde sentido. La trama económica y política domina la empresa periodística, actuando de forma separada y también de modo conjunto como único poder.

Desde un punto de vista económico, la influencia sobre los medios puede contemplarse en un doble aspecto. Por un lado, como presión proveniente de los anunciantes, lo que se vincula directamente con los índices de audiencia, que pueden hacer desaparecer un programa en cuestión porque no tiene un "share" importante y no va a contar con el apoyo publicitario suficiente como para mantenerlo:

"En la actualidad, los medios de comunicación se caracterizan de manera contradictoria. Por una parte, son un servicio público esencial pero al mismo tiempo se han convertido en instrumentos de voracidad publicitaria, donde la idea de servicio público se subordina a la rentabilidad, el estado de derecho queda sometido a la ley de mercado y la libertad de expresión y el derecho a la información son patrimonio de las empresas de comunicación. Al mismo tiempo, los cambios tecnológicos acelerados que trastocan la organización del trabajo cotidiano han incidido en la misma ética del periodista. La falta de reflexión, la desvalorización de una investigación rigurosa, una agenda preconstruida y la búsqueda de una sensibilidad primaria forman parte hoy de la cotidianeidad profesional" (4).

La presión económica se entiende desde el momento que el medio en cuestión es una empresa con intereses en otras facetas del mercado. Es la época de los grandes grupos de comunicación, de tal manera que un medio no es un ente aislado e independiente. Los medios forman parte de empresas respaldadas por bancos y otras corporaciones ajenas al mundo de la comunicación, y esto va a quedar patente como discurso de empresa sin que, en la mayoría de los casos, haya que decirlo. De esta manera, puede producirse la autocensura del profesional de la información. Si conoce en qué terreno se mueve y qué intereses hay detrás de su empresa, si sabe quién le paga y de qué estructura informativa depende, él mismo puede llegar a no contar ciertas cosas:

"Cada vez resulta más raro encontrar espacios de opiniones independientes. Los medios de comunicación, al menos en buena parte de la comunidad andaluza, se han apuntado unánimemente a eso del pensamiento único. Aquí sólo vale el pensamiento del señorito que controle el periódico o la emisora, ya sea la Junta de Andalucía, el gobierno central, la casa consistorial, la confederación de empresarios más próxima o los intereses extemporáneos de los propios editores del medio de turno. (...) El poder, lentamente, como la erosión y como las estalactitas, no sólo ha logrado intervenir con eficacia en que no se le desmadre la canalla, sino que ha logrado consolidar la idea de que los periodistas no tienen por qué tener ideas propias, y si las tienen, que se las guardes. Y más que de una impresión, estamos hablando de una sensación que se percibe a través de los poros, que se transmite en las redacciones, como una nueva mordaza, como si en la Pasarela Cibeles de la falta de orgullo y de dignidad profesional, nos hubiéramos apuntado todos a la autocensura. (...) Y, en tal contexto, los periodistas, que solemos ser frívolos y apresurados, nos creemos de veras que constituimos un cuarto poder, y que debemos defender nuestra ración de dominio. Nos engañamos. Si en nuestro ámbito, hay alguien que realmente sea poderoso, figura en los consejos de administración de nuestras empresas, ya sean públicas o privadas. El resto, seguimos siendo pobrecitos habladores" (5).

Esta presión económica derivada de la estructura informativa actual viene acompañada de una presión política, ya que la mayor parte de los medios de comunicación se constituyen como partidarios de una corriente ideológica. Más concretamente, en nuestro país, podemos constatar la existencia de medios nacionales que siguen el bipartidismo implícito que conocemos en la actualidad.

En los casos de medios de titularidad pública, como pueden ser la radio y la televisión nacional y autonómica, la cuestión se convierte en una polémica continua desde el momento que se utilizan con fines propagandísticos según el partido en el poder. 
Uno de los casos más llamativos y de los que se hizo eco la prensa de referencia fue una entrevista concedida por el actual presidente del gobierno, José María Aznar, al escritor y periodista Fernando Sánchez Dragó para su programa Negro sobre blanco que se emitió en la segunda cadena de TVE el 18 de febrero de 2000, y durante la cual el entrevistador hizo uso de una vehemencia que restó rigurosidad a su trabajo:

"Desde el inicio, Fernando Sánchez Dragó marcó el tono de su larga entrevista con José María Aznar (...) 'Buenas noches, mejores que nunca', fueron las palabras con las que comenzó un encuentro que arrancó en la medianoche y se prolongó durante más de una hora y media. Luego, el autor de Historia mágica de España se lanzó a elogiar al presidente del Gobierno, al que durante todo el encuentro habló de 'tú', tratamiento al que el presidente respondía con un cordial 'Fernando' (...) El momento cumbre llegó cuando político y presentador hablaban del poema If, de Kipling: 'Muchas de la estrofas parecen una definición de tu carácter y de tu estilo político', dijo Sánchez Dragó, antes de pasar a leer versos del escritor británico: ¿Si marchas junto a reyes con tu paso y con tu luz..." (6).

Esta influencia ideológica que puede desvirtuar el trabajo periodístico, se transforma en poder cuando al profesional de la información se le hace partícipe privilegiado de los acontecimientos que dominan la vida social, política y económica de un país. Es entonces cuando los periodistas hablan de tú a tú con políticos, jueces o banqueros, articulándose todos ellos como brazos de un solo poder, como la cúpula que puede manejar incluso los destinos de una nación. Surgen así los periodistas poderosos, temidos y deseados según sean las circunstancias.

El caso más palpable de lo que decimos ocurrió a mediados de los años noventa a través de lo que se conoce como "sindicato del crimen". La denominación de este grupo hay que buscarla a finales de 1992 a partir de un reportaje publicado por el semanario El Siglo titulado "Guerra en la prensa", y en la que se hacía referencia a la presencia en España de dos grupos de editores y periodistas diferenciados. Por un lado, se hablaba de los editores de El País, Jesús Polanco; de Interviú, Antonio Asensio, y de La Vanguardia, la familia Godó, calificándoles como grupo de "los serbios". Por otra parte se hablaba del "sindicato del crimen", donde se incluían periodistas como Luis María Anson, de Abc; Pedro J. Ramírez, de El Mundo, y Jiménez Lozanitos, de la COPE.

Es a partir de este momento cuando se inicia desde los distintos medios y desde distintas tribunas un cruce de acusaciones. Juan Luis Cebrián, consejero delegado de Prisa, se pronunció al respecto en mayo de 1993 en una conferencia pronunciada ante la asamblea de Instituto Internacional de Prensa en Venecia:

"Una veintena de periodistas constituyen un verdadero sindicato de intereses (...) dedicado en ocasiones a extorsionar empresas, sometido en otras al dictado de quienes les pagan y esclavos siempre de su vanidad y sus rencores (...) Periodistas que abiertamente someten su información a los intereses publicitarios de las firmas que los sufragan, que cobran 'impuesto revolucionario' por no difamar o criticar a políticos o empresas determinadas, se erigen luego ante el público con el símbolo de la pureza y el azote de los corruptos (...) Las columnas de los diarios se utilizan en ocasiones como puñales que asesinan famas, conciencias, carreras y vidas privadas sin otra justificación, a veces, que la propia emulación personal del periodista, sus rencores o venganzas, aunque la historia no encierre, ejemplaridad social, no tenga consecuencias para la comunidad y no resulte esclarecedora de nada que no sean las propias ínfulas del informador" (7).

A partir de este momento se inicia una dura polémica entre medios como El Mundo y Abc, y El País, mientras que los periodistas saltan a la palestra a través de comentarios en los que la trama informativa-política se pone de manifiesto con declaraciones como la siguiente, realizada por Jiménez Losantos a Abc en mayo de 1993:

"El País es a la libertad de expresión lo que el felipismo a la democracia, es decir, su negación (...) Cebrián en Venecia denunciaba que en España existe un sindicato del crimen en la prensa de Madrid, en tres periódicos nada menos, que chantajean y corrompen, que mienten y delinquen. Aquí el único crimen es el que viene cometiendo contra la democracia española el sindicatos de intereses del felipismo. Para corrupción, la adjudicación de Canal Plus, la toma por asalto de Antena 3 Radio, vulnerando la ley y la ética" (8).

Esta última referencia nos aporta un dato más, revelador, para entender qué es lo que se estaba produciendo en estos momentos. No sólo se trataba de una trama periodística-política, sino que la cuestión partidista se alzaba sólo como un brazo más en la guerra mediática. A la intención de desalojar del poder al PSOE, se le unía una denuncia explícita por algunos medios de comunicación y periodistas, los mismos que formaban el llamado "sindicato del crimen", sobre los favores que el gobierno de Felipe González estaba proporcionando a Prisa, editora de El País.

La guerra mediática acuña nuevos términos como "felipismo" y "polanquismo", que logran popularizarse a través de los distintos comentarios y columnas de opinión que salen de la mano de un grupo de periodistas, a la cabeza de los cuales se sitúa Pedro J. Ramírez, director de El Mundo.

Si a principios de los noventa, el malestar de los periodistas podía venir marcado por el descubrimiento de ciertos casos de corrupción, que fueron vistos como una "traición" a los principios y al espíritu del partido socialista, la realidad posterior nos demuestra que existen otras cuestiones que entran en juego. Ya no es sólo la limitación de la libertad de expresión la que es denunciada, sino el trato de favor del gobierno al grupo Prisa, lo que pone en seria desventaja al resto de los empresarios de la comunicación en una década en la que en Europa se vive un momento de expansión en este sentido. 
Sin embargo, en un principio, la idea era la renuncia de los casos de corrupción de la etapa socialista, apoyándose para ello en la libertad de expresión. No es de extrañar, por tanto, que aparezcan nombres diversos en estos primeros momentos. De esta manera, en el verano de 1994 se crea en Marbella la Asociación de Escritores y Periodistas Independientes, bajo el pretexto de la "defensa de la libertad de expresión". Entre los fundadores de esta asociación se encuentran escritores que colaboran en prensa y de nombre tan reconocido como Camilo José Cela, Antonio Gala y Francisco Umbral. A ellos, se les suman periodistas, también de reconocido prestigio y calado en la opinión pública, como Luis María Anson, José Luis Balbín, Antonio Burgos, José María García, Antonio Herrero, Federico Jiménez Losantos, Julián Lago, Luis del Olmo, Raúl del Pozo y Pedro J. Ramírez.

Precisamente, el director de El Mundo dio a conocer en su propio periódico las intenciones de la AEPI, tal y como nos relata un reportaje publicado en La Vanguardia en febrero de 1998:

"La AEPI nace en un momento de tensión entre poderes públicos y editores afines frente a los medios y escritores independientes precisamente cuando los hechos probados han dado la razón a quienes denuncian la corrupción política y el desprestigio del régimen que encarna Felipe González" (9)

Es también el mismo reportaje el que nos ofrece más datos sobre la trama, afirmando que desde el ámbito político, la polémica desatada quiso implicar incluso a la corona. Continúa La Vanguardia anotando que cuando el entonces director de Abc, Luis María Anson, se dio cuenta de que la conspiración tras González apuntaba a la corona se sintió impelido a advertir a quien correspondía (sic.). A partir de aquí, un artículo de Juan Villalonga aparecido en el periódico catalán en el verano de 1998 advertía de la conspiración preparada para acabar con Felipe González y que podía salpicar al rey, y tras la que se encontraban nombres de la banca, la judicatura y el periodismo.

Como ejemplo de lo que decimos, apuntamos la publicación de unas fotos del monarca en la cubierta del yate Fortuna en las que aparecía sin bañador, lo que fue editado por la revista italiana Novella, del grupo Rizzoli, accionista mayoritario en la sociedad editora de El Mundo. Además, el diario de Pedro J. y Época, airearon y reprodujeron las páginas de la revista italiana. $\left({ }^{\star}\right)$

Será a partir de este momento cuando algunos periodistas de la AEPI empiecen a retirarse, como en el caso de Luis María Anson y Luis del Olmo. Posteriormente, tras la llegada al poder del PP, este "sindicato del crimen" parece que empieza a perder fuerza o que se mantiene en un segundo plano, una vez que se ha acabado con la etapa socialista. Las convulsiones políticas y mediáticas de años anteriores han dado paso a un ambiente de aparente calma, sólo alterados por circunstanciales acontecimientos, como el despido de Julia Otero de Onda Cero tras la compra de la cadena por Telefónica.

Al margen de estas cuestiones, se mantienen las buenas formas, a pesar de que el análisis de los hechos nos presente similitudes en el terreno de los medios de comunicación entre el gobierno socialista y el popular:

$-1^{\circ}$.- Es en 1989, cuando el gobierno socialista concede una de las licencias de TV a Canal Plus, del grupo Prisa, perteneciente de forma mayoritaria a Jesús Polanco.

La crítica viene a partir de entonces marcada por otros medios, como El Mundo y Abc, que acusarán a Polanco de ser el "sostén mediático del felipismo".

$2^{\circ}$.- Mientras, comprobamos cómo en el año 2000, el gobierno del Partido Popular concede dos licencias de TV nuevas, una al consorcio NetTV, liderado por E-media ( $25 \%$ del capital) y compañía con la que Prensa Española, editora de Abc, participa en el mercado multimedia; y la otra al consorcio Veo TV, con Grupo Recoletos $(25,5 \%)$ y Unidad Editorial, editora de El Mundo, con un $25,5 \%$, y el apoyo de Iberdrola (20\%).

La crítica vendrá esta vez hecha por El País, que en su editorial acusa al gobierno de Aznar de conceder las licencias a medios de su "entorno inmediato".

En ninguno de los dos caso podemos demostrar de forma empírica el favorecimiento de cada uno de los gobiernos sobre unos grupos concretos, pero el análisis de los hechos demuestra que en ambos casos se produjeron adjudicaciones de licencias a grupos que han mostrado su apoyo a la política del partido en el poder.

De esta forma, el entramado político-mediático-económico se alza como una de las claves para entender el papel de los medios en la actualidad y, por ende, el papel del periodista. Su labor se va a ver así limitada desde el momento que se realiza en un contexto determinado, dentro de una empresa concreta con intereses muy definidos, ideológica y económicamente.

Asistimos así hoy a la consideración de una presión no explícita, pero sí implícita, que no se reconoce en muchos casos y que se maquilla siempre bajo el velo de "independencia". La necesidad de reflexionar sobre la función social que ha de cumplir el periodista y la consecuencia de proceder a una autocrítica se configuran como cuestiones inmediatas para retomar el importante papel que el informador tiene en la sociedad. 
Las siguientes palabras de Félix Santos nos sirven como recomendación final a tener en cuenta en el ejercicio de la profesión periodística:

"Hemos visto que los medios de comunicación cumplen muchas funciones en la sociedad. Son también la voz de la nación y una de sus imágenes más visibles. Los periodistas también tenemos responsabilidades ante nosotros mismos y ante el país. Como escribió el gran periodista, de ascendencia española, que fue Albert Camus: "La tarea de cada uno de nosotros es la de pensar bien lo que nos proponemos decir, modelar poco a poco el espíritu de nuestro periódico, escribir lúcidamente y no perder jamás de vista la inmensa necesidad que tenemos de dar al país su voz profunda. Si hacemos que esta voz sea la de la energía en vez la del odio, de la orgullosa objetividad y no de la retórica, de la humanidad antes que de la mediocridad, entonces muchas cosas se habrán salvado y nosotros no habremos defraudado" (10).

(Recibido el 15-9-2000, aceptado el 23-10-2000)

NOTAS:

(1) Vid. BARRERA DEL BARRIO, Carlos: Del gacetero al profesional del periodismo, Fragua Editorial, Madrid, 1999.

(2) Vid. LABIO BERNAL, Aurora: Diario de Cádiz: historia y estructura Informativa (1867-1898), pp. 259-262.

(3) REIG, Ramón: "Política y periodismo: lo que la estructura ha unido que el rigor no lo separe", en El Periodista como actor político, monográfico de Estudios de Periodística VIII, Sociedad Española de Periodística, Universidad de Vigo, 2000. p. 183.

(4) MARTíNEZ ROMERO, José Ramón: "Los mass media: ¿un poder sin contrapoder?, en AA.VV.: Periodistas, hoy, Federación Andaluza de Asociaciones de Prensa, Sevilla, 2000, p. 40.

(5) TÉLLEZ, Juan José: "Mecanismos de intervención del poder sobre los periodistas", AA.VV.: en Periodistas... Op. Cit. , p. 21.

(6) El País, martes, 20 de febrero de 2001, p. 61.

(7) Cit. por SANTOS, Félix: Periodistas, Ediciones Temas de Hoy, Madrid, 1995, pp. 213-214.

(8) Ibídem. p. 215.

(9) Cit. en "Resumen de la conspiración", La Vanguardia, 22 de febrero de 1998. Vid. http://www.aznar.net/laconspiracion.htm, p. 2.

(10) SANTOS, Félix: Periodistas, Ediciones Temas de Hoy, Colección España Hoy, Madrid, 1995, p. 265.

\section{FORMA DE CITAR ESTE TRABAJO EN BIBLIOGRAFÍAS:}

Labio Bernal, Aurora (2002): La profesión periodística ante los intereses de la estructura informativa. Una aproximación al tema. Revista Latina de Comunicación Social, 46.. Recuperado el x de xxxx de 200x de: http://www.ull.es/publicaciones/latina/2002/latina46enero/4610bernal.htm 